\title{
Juvenile retinoschisis, anterior retinal dialysis, and retinal detachment
}

\author{
J. RICHARDSON \\ Sunderland Eye Infirmary
}

Ringland Anderson (1932) coined the term "anterior retinal dialysis" to describe dehi $\frac{2}{0}$. scence of the retina at the ora serrata, because of its resemblance to iridodialysis. As he் and others (Shapland, I 934, I 949; Leffertstra, I950; Duke-Elder and Dobree, 1967) have noted, this condition is the commonest cause of retinal detachment in young people $\underset{\star}{\dot{\omega}}$ The dialysis results from trauma in about one-quarter of the cases; the nontraumatic casef have an uncertain aetiology.

Many authors have emphasized the overwhelming predilection of these dialyses for the infero-temporal area of the fundus, especially where the dialysis is nontraumatic (Shapland I 934, 73 per cent. of I I 3 cases; Shapland, I 948, 90 per cent. of 22 cases; Leffertstra, I 950\%, 83 per cent. of 200 cases).

Bilaterality is another feature of the condition. Kornzweig (1940) cited Schmelzer (1936), who reported two brothers, aged 25 and 32 years, with bilateral lower-half retinab detachments and infero-temporal anterior retinal dialysis.

Shapland (1948) had seen this in 1938 in a 28-year-old man. Shapland (1949) remarked

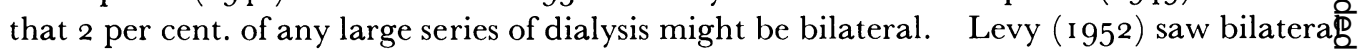
infero-temporal anterior retinal dialysis in a young man, with a related retinal detachmen $\vec{E}$ in one eye.

Leffertstra (1950) found I4 per cent. of 200 cases to be bilateral; in 71 cases in whicl scleral depression was used during examination the proportion showing bilaterality was 20 per cent.

Weve (1936) first suggested that nontraumatic dialysis might be due to anteceden cysts of the ora serrata. Shapland (1945) referred to "rupture of retinal cysts causing. retinal detachments". Stallard (1946), reporting two cases of unusual upper tempora cystic detachments in young men, remarked that twelve of thirteen such cases, i.e. cystio detachments, seen in the Middle East Forces during the second world war, developed tearsp seven multiple. In two cases the cystic detachment spread, causing macular detachment and this experience prompted him to recommend prophylactic surgery in the two cases he reported.

Others had noticed bilateral cystic detachments without tears (Ridley, I935, I936 Kornzweig, 1940), some in older people but mostly in young men.

Duke-Elder ( 1949) reported a case of peripheral retinal cyst in a 44-year-old man leading to anterior retinal dialysis and retinal detachment. This followed a period of enlargemen黑 of the cyst.

In his series of 200 cases of anterior retinal dialysis from Weve's clinic, Leffertstra ( $1950 \Phi_{\overparen{\Phi}}^{\circ}$ found that 53 of 228 eyes showed retinal cysts in addition to their dialysis and retina detachment. There were cases with multiple cysts and, in all, I 05 cysts were counted $\stackrel{\mathbb{D}}{\mathscr{Q}}$ Leffertstra defined retinal cyst as "a greater or smaller, round or oval vesicle, of greater o 
lesser transparence, bulging partly in the vitreous, partly in the subretinal space". 65 cysts were noted in the "central margin of the tear", eleven next to the end of the tear, and 29 elsewhere in the retina. He felt that the large number of "central margin" cysts supported Weve's idea of the cyst lifting up the formerly intact retina and tearing it at the thinnest place (see Discussion).

"Cysts of the ora serrata" (Weve, I936), cystic detachments, and retinal cysts, as described by the authors mentioned above, are now considered to be cystic retinal swellings due to retinoschisis.

\section{Definition}

Retinoschisis means bilamination of the neural retina with consequent elevation of the inner lamina and formation of a fluid-filled cavity (Duke-Elder and Dobree, r 967).

There is no consensus among authorities on the clinical classifications of retinoschisis. Terminology is confused; in particular, as Keith (1966) suggested, clinicians have used "retinal cyst" and "retinoschisis" synonymously, whereas the latter is the process by which the former arises. The term 'cyst' is used to describe a fluid-filled cavity, not a cavity lined by epithelium with a discrete wall, which is the true pathological definition of a cyst.

Where the retinoschisis is primary, three distinct clinical varieties may be recognized:

(I) Senile Developing in patients over 40 years of age (Shea, Schepens, and von Pirquet, I960).

(2) Congenital Presumed present at birth, often hereditary, and usually sex-linked (confined to males). These patients present with ocular defects early in life, often within the first year (Brockhurst, I970; Sorsby, Klein, Gann, and Siggins, I95 I ; Duke-Elder and Dobree, I967).

(3) Fuvenile Presenting usually in the third and fourth decades, invariably in males, affecting the infero-temporal retina, often bilaterally. Usually symptomless, the condition is often discovered on routine fundoscopy. Clearly, unilateral or bilateral symmetrical retinoschisis of this type may be seen before or after the two decades mentioned.

Characteristically the senile variety has a slow peripheral progression, rarely threatening central vision and rarely requiring treatment (Shea and others, i960). The congenital form often progresses quickly and is associated with macular, vitreous, and lenticular disorders (Sorsby and others, I95 I ; Levy, I 952; Duke-Elder and Dobree, I967). Juvenile retinoschisis may exhibit slow progression (Pischel, i 965), but more seriously, we believe, as suggested by Weve, it may predispose the patient to retinal detachment by causing anterior retinal dialysis.

\section{Pathogenesis}

In senile retinoschisis bilamination results from "enlargement and/or confluence of microcysts of the peripheral retina" (Zimmerman and Spencer, I96o; Shea and others, I96o; Curtin, Norton, and Smith, I960). Teng and Katzin (1953) noted that microcystoid degeneration of the peripheral retina "is usually found only in patients over 40 years of age, sometimes at a younger age".

The pathogenesis of congenital retinoschisis is unknown. The pathogenesis of juvenile retinoschisis is uncertain but is likely to differ from that of senile retinoschisis in view of the different clinical features. It may arise from congenital epithelial nests of cells which grow and later become cystic, as suggested by Weve (1936). Apart from this factor of 
congenital nature, its pathognomonic infero-temporal location may be a result of the actior of one or more of the following factors:

(i) Inadequate vascularization in the peripheral retina;

(ii) Vitreous and zonular "tug";

(iii) Poor vitreal support to the retina as a result of the thin nerve fibre layer in the peripheral retina-especially infero-temporally.

Juvenile retinoschisis, like anterior retinal dialysis, occurs in young men, affects the infero-temporal retina, and is often bilateral.

\section{Case reports}

In four recent cases of nontraumatic anterior retinal dialysis, retinoschisis was present andwas observed in one case even before the development of anterior retinal dialysis and retinal detachment. Two of the four cases were bilateral.

Case 1, a young man aged 21 years, was first seen on November 6, 1970, with poor vision in theूّ left eye which had been discovered on routine vision testing when he was applying for a job with and electronics firm. He was referred to hospital via the optician and home doctor.

\section{Examination}

The left fundus showed an infero-temporal anterior retinal dialysis encompassed by a large area ob retinoschisis and central to this a retinal detachment which had spread to involve the maculas Vision was $\mathrm{I} / 60$ with $+0.5 \mathrm{D}$ sph. (Fig. $\mathrm{I}: \mathrm{I}$ ).

The right fundus showed an infero-temporal retinoschisis with multiple round holes in the innex lamina but no retinal detachment and no dialysis. The vision was $6 / 6$ with $+0 \cdot 5 \mathrm{D}$ sph., -0.25 D.cyl, axis $90^{\circ}$.

\section{Operation}

A left retinopexy was carried out on November 12, 1970. A silicone implant was placed in scleral pocket in the lower temporal quadrant and an encircling silicone band was strapped over the implant (Schepens and Freeman, 1967). Cryoapplications anterior, posterior, and within the bed of the scleral pocket were made. Subretinal fluid was released by catholysis puncture posterion to the scleral pocket.

Result

The retina remained flat after operation but the central vision did not materially improve; refraction on December 4 was $-3 \mathrm{D}$ sph., $+0.75 \mathrm{D}$ cyl., axis $65^{\circ}$, giving $3 / 60$. At a routine follow-up visi on September 13, 1971, the right fundus was found to show an anterior retinal dialysis in relation to the retinoschisis and a retinal detachment approaching the macula (Fig. 1:2).

Second operation

On September 16, 197 I, a silicone implant and encircling band was applied, along with cryoapplica涩 tion and catholysis puncture, as for the left eye.

Result

The retina has remained flat since the operation. On December 24, 1971, refraction was $-3 \mathrm{D}$ sph. - I D cyl., axis $90^{\circ}$, giving 6/4 part. 

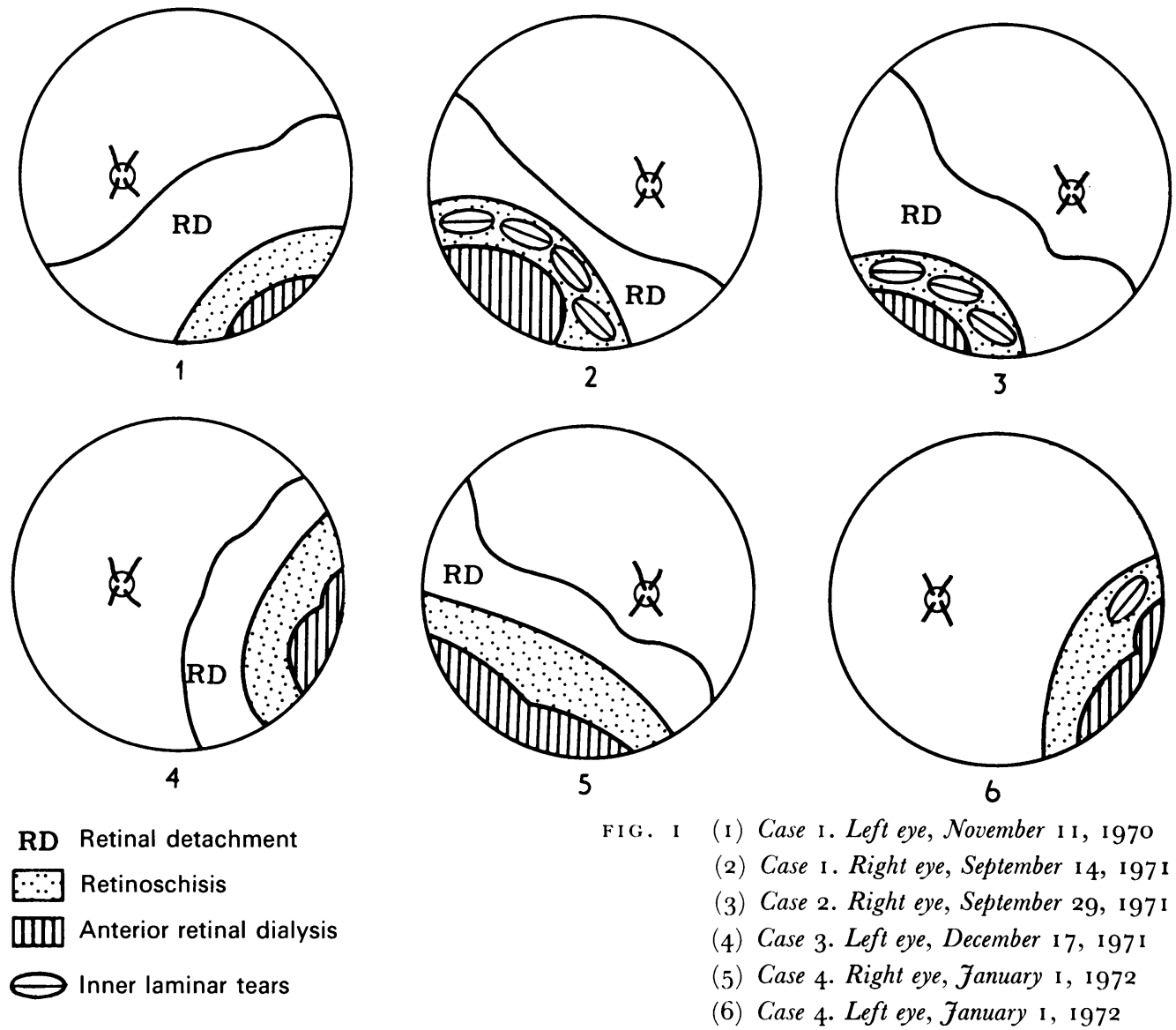

Case 2, a man aged 31, was referred from an optician via the home doctor on September 27, 197 I, with a large right retinal detachment.

\section{Examination}

The visual acuity was hand movements in the right eye. Fundoscopy showed an infero-temporal dialysis with adjacent retinoschisis with multiple inner laminar holes, and central to this a large area of retinal detachment (Fig. $1: 3$ ).

The visual acuity in the left eye was $6 / 18$ unaided and the fundus was normal.

Operation

On October I, I97 I, the procedure described above was again used.

Results

The retina has remained flat since operation but the central vision has not improved.

Case 3, a man aged 29, was first seen on December I 7, I97 I, with 6 weeks' history of deteriorating vision in the left eye. 


\section{Examination}

The visual acuity in the left eye was $6 / 12$ with - I D sph., and fundoscopy showed a left temporal dialysis, retinoschisis, and retinal detachment (Fig. $1: 4$ ).

In the right eye the visual acuity was $6 / 4$ unaided and the fundus was normal.

Operation

A left silicone band and implant with cryoapplication and catholysis was performed on December I

Result

The retina has remained flat since the operation and on January 1,1972 , the refraction was $-2 \overrightarrow{\mathrm{B}}$ sph., - I D cyl., axis $120^{\circ}$, giving $6 / 6$ vision (distorted).

Case 4, a man aged 31 years, was first seen on January 3, 1972, complaining of distortion ồ vision in the right eye of recent onset.

Examination

The visual acuity was $6 / 9$ in the right eye with $-7 \mathrm{D}$ sph., - I D cyl., axis $180^{\circ}$. Fundoscop $\vec{y}$ showed infero-temporal anterior retinal dialysis, retinoschisis, and retinal detachment (Fig. I:5) In the left eye the visual acuity was $6 / 5$ with $-6 \mathrm{D}$ sph., $-2 \mathrm{D}$ cyl., axis $180^{\circ}$, and there was an infero-temporal anterior retinal dialysis with retinoschisis but no retinal detachment (Fig. $\mathrm{I}: 6$ ).

\section{Operation}

Retinal surgery was performed on the right eye on January 6,1972 , as described for the previous cases.

Result

The retina has remained flat.

Second operation

Cryopexy was applied over the sclera beneath the infero-temporal retinoschisis in the left eye of January 20, 1972.

\section{Discussion}

In Case I, anterior retinal dialysis and true retinal detachment were seen to develop in relation to a known area of retinoschisis; no doubt the same sequence of events occurred in the fellow eye. In Case 4, we saw retinoschisis and anterior retinal dialysis only in the one eye, the contralateral eye having developed retinal detachment in addition. Cases 2 and are examples of the full-blown syndrome-retinoschisis, anterior retinal dialysis, an $\mathbb{}$ retinal detachment.

It seems likely that, in all four cases, three stages of progression occurred. In stage retinoschisis only is present, and at this time there may be holes in the inner lamina; in Stage 2 anterior retinal dialysis develops; finally in Stage 3 retinal detachment occurs?

If we postulate that these retinoschises grow in size continuously, then this will leas either to inexorable central progression, i.e. towards the posterior pole, and/or to peripherat progression, i.e. circumferentially. Should the spreading edge of the retinoschisis be fixed and the splitting process halted, then enlargement of the 'schisis cavity can occur only bo steady protusion of the inner lamina into the vitreous cavity. At this time inner lamina孚 holes may well appear. Later a dialysis may arise in two ways : 
(I) The whole 'schisis may rotate about the posterior fixed limit, thereby tearing its peripheral attachment free at the ora (Fig. 2a, b) and leading to retinal detachment without "cystic rupture" as postulated by Weve (1936). This would then give the clinical picture of a discrete "cyst" within the confines of a true retinal detachment, rather as described by Leffertstra (1950).
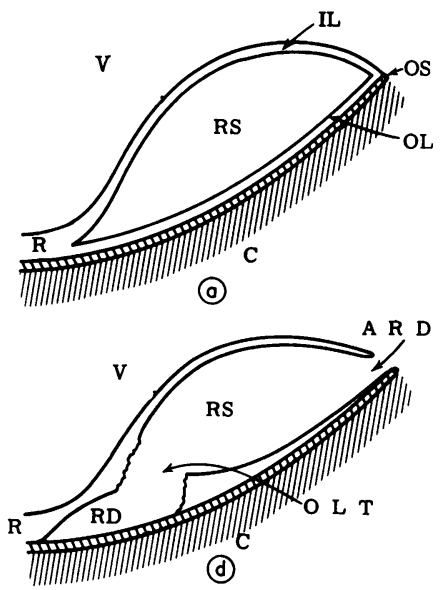

(d)

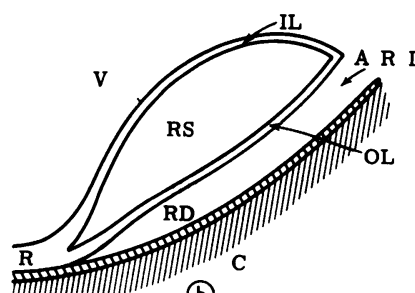

(b)

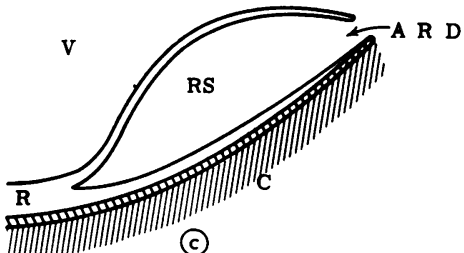

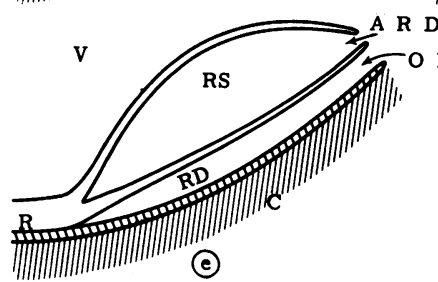

(b) After anterior retinal

FI G. 2 (a) Before anterior retinal dialysis dialysis $(c)(d)(e) \quad$ See text

(2) Perhaps more commonly, dialysis may be produced by the "bursting" of the retinoschisis when a critical size is reached, the inner lamina tearing along the ora serrata (Fig. 2c). We consider this may well have happened in the left eye of Case 4. However, a sequential dehiscence in the outer lamina of the 'schisis, either at its posterior limit (Fig. $2 d$ ) or at the ora (Fig. 2e), permits the development of a retinal detachment and would produce the appearances we have seen in the cases we have described with retinal detachment. In such cases there is no discrete cystic swelling in the "detached retina" and the true origin of the anterior retinal dialysis in a retinoschisis may be overlooked.

Keith (1966) drew attention to the fact that anterior retinal dialysis due to retinal bilamination had not been described in childhood, as one might expect (Hudson, 1965). However, if, as seems likely, anterior retinal dialysis occurs only when the 'schisis cavity reaches a critical size, then it may be that this size is usually achieved, by progression of the retinoschisis, only after adolescence. Keith also commented that patients with anterior retinal dialysis induced by retinoschisis should be seen with an "intact cyst" in the contralateral eye before cystic rupture, if, in fact, retinoschisis does predispose to anterior retinal dialysis-Case I above is, in fact, just such a case.

The impressive anatomical coincidence between the location of anterior retinal dialysis and juvenile retinoschisis, together with the clinical features of previous cases and the ones described, offers strong support for Weve's hypothesis that anterior retinal dialysis, especially when nontraumatic, often occurs at the site of pre-existing retinoschisis or, as he called it, "cyst of the ora serrata".

In view of the risk of progression of juvenile retinoschisis, Pischel (1965) used light coagulation direct to the 'schisis cavity to prevent progression. Prophylactic treatment does appear to be justified in view of the risk of progression but also in view of the risk of 
anterior retinal dialysis. Brockhurst (1970) showed that coagulation of these lesions ma lead to retinal hole formation and we have preferred cryopexy in the one case treated prophylactically so far.

Where detachment has occurred we have preferred the band and implant procedure, by the method of Schepens and Freeman (1967), described above. We feel that a lastinf indentation is required in these cases. In traumatic cases conservative measures can ofte be used (Blach and Davies, I967), since in such cases the retina flattens when the patien rests in bed. For these we use light coagulation, but there is little tendency for the retinf to flatten in cases in which the condition is due to spontaneous dialysis.

\section{Summary}

The role of juvenile retinoschisis in the aetiology of anterior retinal dialysis in young adults is discussed and support is given to Weve's hypothesis. Four cases are reported, and the management of such cases is briefly discussed.

I should like to thank Mr. J. R. Hudson for his kind advice and comments on Case 4 .

\section{References}

ANDERSON, J. RINGLAND (1932) Brit. J. Ophthal., 16, 641

BLACH, R. K., and DAVIES, E. W. G. (1967) Trans. ophthal. Soc. U.K., 87, 317

BROCKHURST, R. J. (1970) Arch. Ophthal. (Chicago), 84, 158

Curtin, v. T., Norton, E. w. D., and SMith, T. R. (1960) A.M.A. Arch. Ophthal., 63, 978

DUKE-ELDER, s. (1949) Brit. F. Ophthal., 33, 388

and DOBREE, J. H. (1967) "System of Ophthalmology", vol. Io. Kimpton, London

HuDson, J. R. (1965) Trans. ophthal. Soc. U.K., 85, 79

KEITH, G. G. (1966) Brit. F. Ophthal., 50, 6 I 7

KORNZWEIG (1940) Arch. Ophthal. (Chicago), 23, 49 I

LEFFERTSTRA, L. J. (1950) Ophthalmologica (Basel), 119, I

LEVY, J. (1952) Brit. 7. Ophthal., 36, 626

PISCHEL, D. K. (1965) Trans. ophthal. Soc. U.K., 85, 67

RIDLEY, H. (1935) Brit. F. Ophthal., r9, Io I

(1936) Ibid., 20, 65

SCHEPENS, C. L., and FREemAN, H. M. (1967) In "Modern Trends in Ophthalmology-4", edi

A. Sorsby, p. 209. Butterworths, London

SGhmelzer, H. (1936) Klin. Mbl. Augenheilk., 96, i9

SHAPLAND, C. DEE (1934) Brit. F. Ophthal., 18, I

- (1945) Amer. 7. Ophthal., 28, 324

(1948) Trans. ophthal. Soc. U.K., 68, I 15

(1949) Proc. roy. Soc. Med., 42, 609

SHEA, M., SCHEPENS, c. L., and von PIRQUET, s. R. (1960) A.M.A. Arch. Ophthal., 63, I SORSBY, A., KLEIN, M., GANN, J. H., and siggins, G. (195I) Brit. J. Ophthal., 35, I

STALLARD, H. B. (1946) Ibid., 30, 547

TENG, c. C., and kAtzin, н. м. (I953) Amer. 7. Ophthal., 36, 29

WEVE, H. (1936) Arch. Augenheilk., I09, 49

zimmerman, L. E., and SPENCER, w. H. (1960) A.M.A. Arch. Ophthal., 63, 10 